\title{
Evaluation of Masseter Muscle Dimensions Through Ultrasonography
}

\author{
Evaluación de las Dimensiones del Músculo Masetero Mediante Ultrasonido
}

\author{
Ana Paula Reis Durão1; Magda Daniela Amaral Ribeiro²; Marcelo Miranda ${ }^{3}$ \& Aline Rose Cantarelli Morosolli ${ }^{4}$
}

DURÃO, A. P. R.; RIBEIRO, M. D. A.; MIRANDA, M. \& MOROSOLLI, A. R. C. Evaluation of masseter muscle dimensions through ultrasonography. Int. J. Odontostomat., 15(4):980-988, 2021.

ABSTRACT: The objective this study was to determine mean values of masseter muscle thickness in male and female, at rest and contraction, in healthy individuals.At first, 102 questionnaires were distributed between students. Thirty patients were selected, 15 male and 15 female, according to the inclusion criteria, excluding all individuals with symptoms of temporo-mandibular dysfunction or syndromes with craniofacial disorders. Masseter muscle thickness was determined bilaterally, at rest and contraction. As a reference point for the measurement of thickness (axial plane), the posterior prolongation of the labial commissure was used. Normality values of the masseter muscle in females were $11.75 \pm 1,14 \mathrm{~mm}$ in contraction and $10.19 \pm 1.04 \mathrm{~mm}$ in relaxation; and in the male were $13.95 \pm 1.62 \mathrm{~mm}$ in contraction and $11.64 \mathrm{~mm} \pm 1.68 \mathrm{~mm}$ in relaxation. The results obtained are in agreement with those described in the literature. Demonstrating the accuracy and reproductibility of the ultrasound if a protocol is applied, mainly aimed at controlling the pressure applied by the transducer.

KEY WORDS: masseter muscle, ultrasound, ecography, thickness, craniofacial morphology.

\section{INTRODUCTION}

The masseter muscle (MM) has relevance in kinematics, mandibular growth, and facial aesthetics (Frugone et al., 2010; Oliveira et al., 2015). It presents a complex internal structure, with numerous aponeuroses and two main portions: One superficial and another deep; formed since muscle fibers with different orientations, responsible by creation of numerous force vectors with different function in the mandibular movement (Kubo et al., 2006).

The development and functioning of the MM occur in an organized and planned manner, according to the functional and environmental stimuli to which it is subject (Palinkas et al., 2010). Thus, the study of this muscular structure is fundamental for the morphofunctional characterization of the craniofacial complex, which may include the morphological, histological study and eventual electrical activity (Oliveira et al.).
The evaluation of the structure of muscle fibers is possible using imaging methods such as Computed Tomography (CT), Magnetic Resonance (MR) and Ultrasound, this, given its viability in the dynamic and static study of the musculature, presents itself as the method of excellence for assessing MM thickness (Oliveira et al.; Close et al., 1995). The ultrasound is an accessible, low-cost, non-invasive test, capable of ensuring uncomplicated visualization of facial structures, particularly useful in assessing the transversal dimension of MM invivo (Oliveira et al.; Bakke et al., 1992; Close et al.). Since that strict protocol is followed, reproducibility and viability are ensured for muscle measurement, which allows the acquisition of objective and easily comparable parameters (Oliveira et al.; Satirog lu et al., 2005). MM thickness has been widely studied (Kiliaridis \& Kälebo, 1991; Bakke et al.; Raadsheer et al., 1996; Emshoff et al., 2003; Satirog lu et al.; Georgiakaki et al., 2007), however, heterogeneity

\footnotetext{
${ }^{1}$ Faculty odf Healh Sciences, University Fernando Pessoa, Porto, Portugal.

2 Postgraduate student, Integrated Master's Program in Dental Medicine, Faculty of Dental Medicine, University of Porto, Portugal.

${ }^{3}$ Department of Dental Radiology, Faculty of Dental Medicine, University of Porto, Portugal.

${ }^{4}$ Adjunct Professor, discipline of Radiology, Dentistry Course, School of Health and Life Sciences, Pontifical Catholic University of Rio Grande do Sul, Porto Alegre, Brazil.
} 
of the measures observed in the literature could be minimized by subdividing the muscle into segments and standardizing the number of measures for a morphometric analysis (Reis Durão et al., 2017).

Dysfunctional contraction mechanisms are responsible for modifying the muscle structure, including its thickness, through edema and / or muscle hypertrophy (Aldemir et al., 2013). Excessive load generates an imbalance in the various mechanisms of the craniofacial complex through a transient inflammatory condition, or a definite increase in muscle thickness (Kiliaridis et al., 2010; Ariji et al., 2010).

Several authors used the ultrasound to understand the correlation of MM dimensions with factors such as age, sex, bite force, facial type, arcade shape and occlusion, reinforcing the morphofunctional importance of this muscle, as well as its relevance in maintaining integrity of the stomatognathic system (Bakke et al.; Satiroglu et al.; Palinkas et al.). The quantification of the masseter thickness is possible due to its superficial location (Ariji et al., 2004) and it becomes crucial for the evaluation of the masseter muscle morphology and consequent detection of asymmetries and hypertrophy. The data obtained in different investigations are important for the study and treatment of different pathological conditions inherent to the stomatognathic system, allowing the creation of clinical protocols based on values reference for each sex, enhancing the diagnosis and treatment of the respective conditions (Frugone et al.).

Thus, the objective of the present study is to determine the thickness of the MM, through ultrasound, correlating with lifestyle and nutritional habits for both sexes.

\section{MATERIAL AND METHOD}

Sample selection: The study was approved by the Ethics Committee of the Faculty of Dental Medicine of the University of Porto (Approval $n^{\circ} 22$ ). One hundred and two volunteer students from the same university were approached. Each participant consented to participate in the study by signing the informed consent. Subsequently, an intra and extra-oral evaluation was carried out with the respective data collection form.

To guarantee the acquisition of the normality standard for MM thickness, all individuals who presented loss of dental parts, except third molars and / or premolars, prosthesis or orthodontic treatment, history of orthognathic treatment, facial trauma, were excluded, mandibular fracture, injection of botulinum toxin in the face and individuals with a history of neuromuscular diseases, craniofacial disorders, and symptoms and / or temporomandibular disorders.

In the second phase of data collection, all previously described parameters were applied, 30 individuals were selected, 15 females and 15 males.

Ultrasound analysis. The ultrasound determination of the MM thickness was assessed by a radiologist doctor with 30 years of experience and a maxillofacial radiologist with 15 years of experience. In cases of disagreement between the observers, consensus was reached by discussion. The ultrasound used were performed at the GE Healthcare (unit of the General Electric Company, United Kingdom), with a $12 \mathrm{~mm}$ linear type transducer. The ultrasound evaluation was performed in an appropriate room for diagnostic imaging exam, with low light intensity.

Patient position. All participants remained seated in a supine position - Frankfurt plane parallel to the floor, without any means of fixing the head, with their eyes open and their hair removed from the face. The location of the MM was detected by instructing the patient to perform strong maximum intercuspation with palpation of the anterior margin, followed by moving the linear transducer for confirmation. Once the muscle was located, a water-based gel was applied to the area between the posterior and anterior edge of the mandible branch, keeping the transducer in a position perpendicular to the skin, with reduced pressure (Fig. 1).
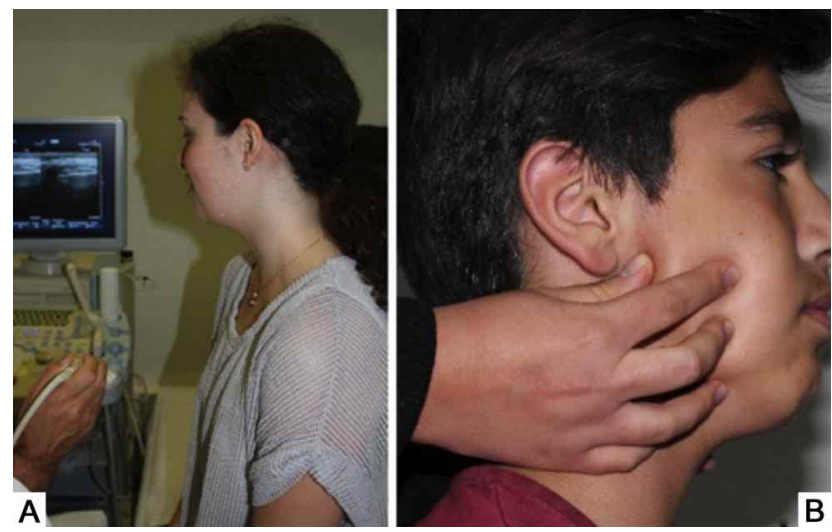

Fig. 1. Patient position for ultrasound examination and determination of muscle location.

A. Patient's supine position. Note the head 'position.

B. Location of the masseter muscle through clinical examination - muscle palpation. 
The images were taken bilaterally under the two conditions described, at rest and maximum intercuspation (maximum contraction of the MM). During image acquisition, the patient was asked to slightly rotate his head to the side contralateral to the one under analysis.

To determine the thickness of the muscle (in the axial plane), the posterior extension of the labial commissure was used as an anatomical reference (Fig. 2).

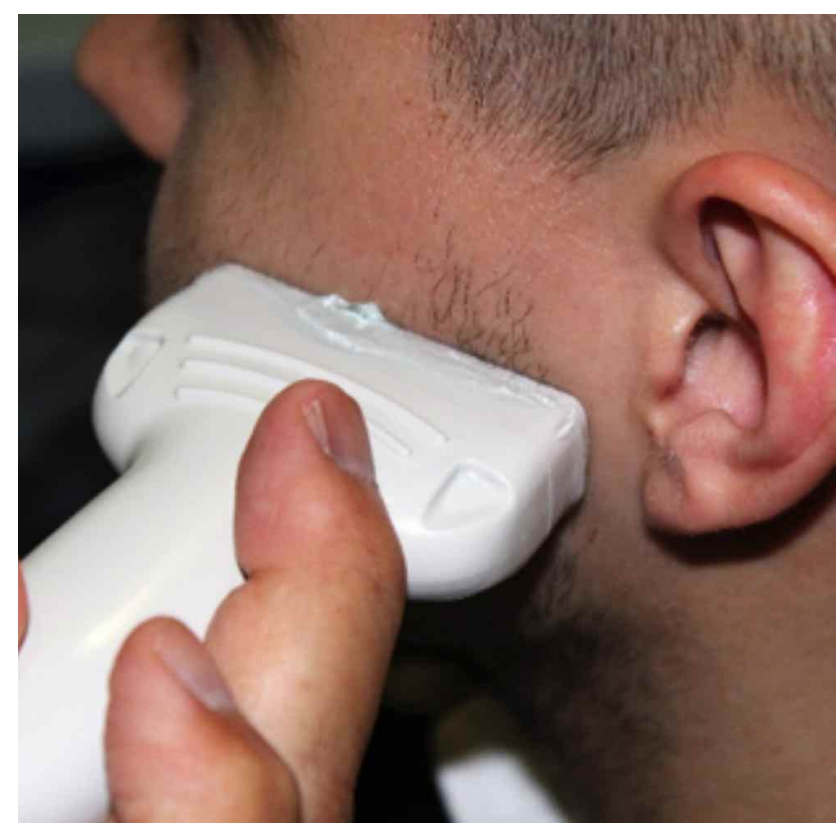

Fig. 2. Position of the linear transducer during ultrasound image acquisition.

Measurements. The measurements were obtained in real time and directly on the image, to the nearest $0.1 \mathrm{~mm}$ (Figs. 3 and 4).

Statistical analysis. The descriptive analysis of the data was performed using Excel $囚$ software (Version 2016; Microsoft, Redmond, Washington - USA) and the statistical software SPSS $®$ (Statistical Package for Social Sciences 24.0 for Windows, SPSS Inc., Chicago, Illinois - USA), also used for statistical analysis.

The description of the data is presented through an analysis of percentages for the variables sex, lifestyle and nutritional habits and determination of the mean \pm standard deviation for the continuous variables, age, and height.
In the statistical analysis of the cases, a significance level of $a=0.05$ was defined for all tests. Intraobserver and interobserver reliability were evaluated by Kappa statistics. The Shapiro-Wilk test was applied to assess the normality of the values obtained in the two groups under study.

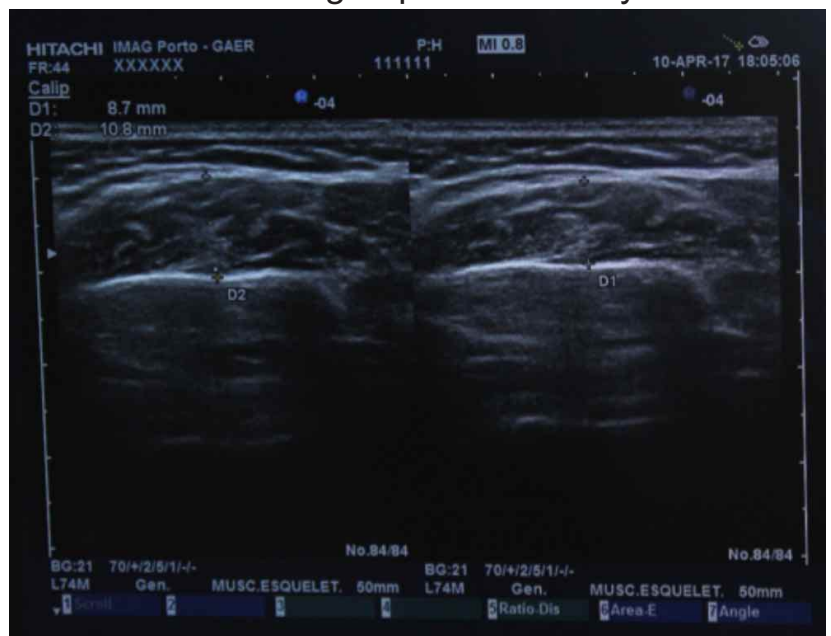

Fig. 3 Measurement in contraction and rest.

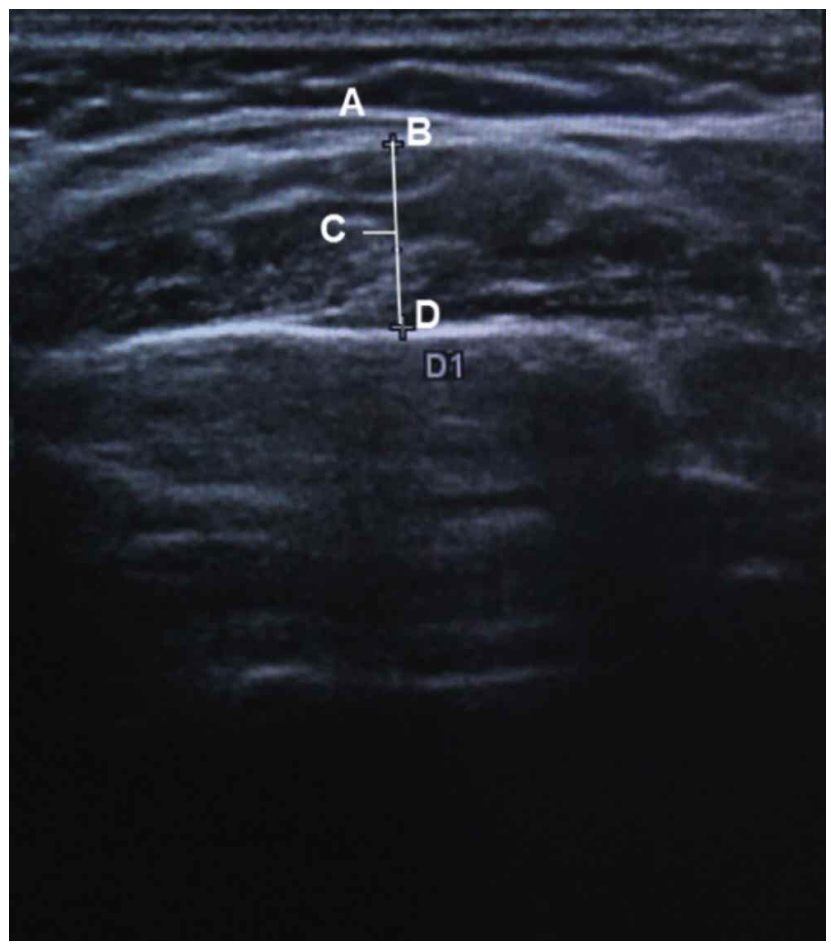

Fig. 4. Image obtained by ultrasound.

A - White shadow represents the most superficial structure skin.

B - Upper limit represented by a white trace representing the muscular fascia.

C - Heterogeneous dark area corresponds to the transversal dimension of the muscle.

D - Lower limit represented by a white image corresponds to the lateral surface of the mandibular ramus. 


\section{RESULTS}

Descriptive analysis of the population sample. Intra- and inter-observer correlations were found excellent for all the evaluations $(0.91$ and 0.85 , respectively). Of the 60 ultrasounds performed, 30 correspond to women and 30 to men. The ages of the patients included in this study at the time of data collection vary between 19 and 30 years old, with an average of $23.5 \pm 2.3$ and a median of 23 years. The graph in Figure 5 describes the distribution of the sample population by age group according to sex.

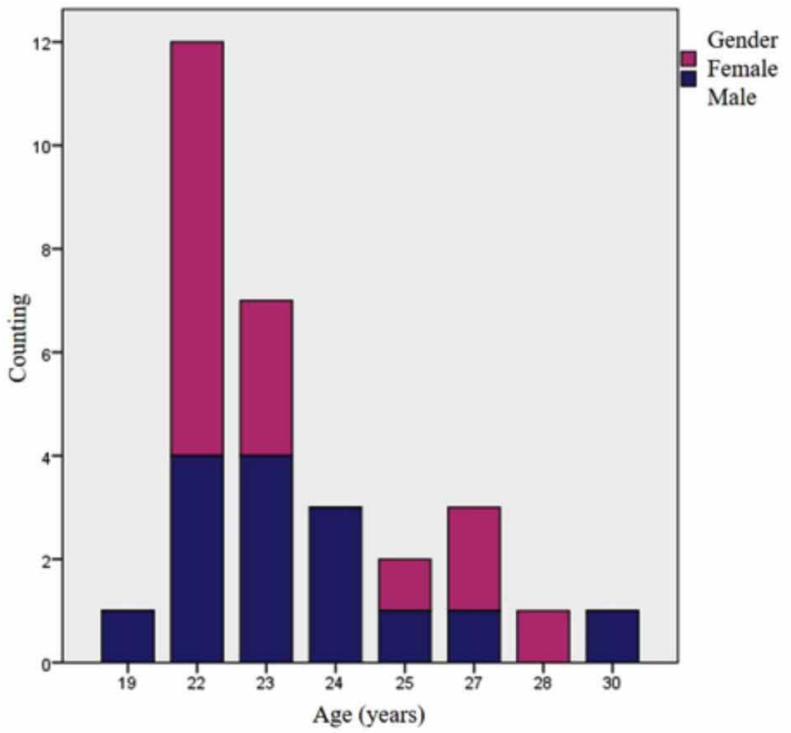

Fig. 5. Representative graph of the sample population by gender and age

The heights of the individuals included in this study at the date of data collection vary between $157 \mathrm{~cm}$ and $195 \mathrm{~cm}$, with an average of $169.87 \pm$ $8.20 \mathrm{~cm}$. The Fig. 6 describes the distribution of the sample population by height according to sex (Fig. $6)$.

Regarding nutritional habits, $26.7 \%$ of individuals, on average, have seven "Meals with meat per week". Figure 7 represents the distribution of the number of meat meals per week.

$70 \%$ of the individuals in this study presented "Lifestyle: Active" and $30 \%$ pf the individuals presented "Lifestyle: Pasive".

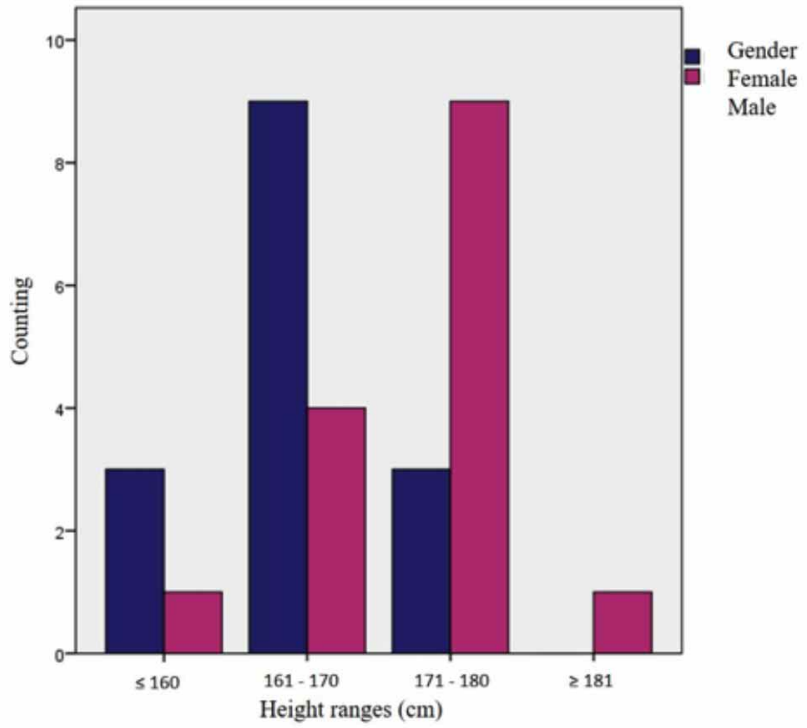

Fig. 6. Representative graph of the sample population by gender and height

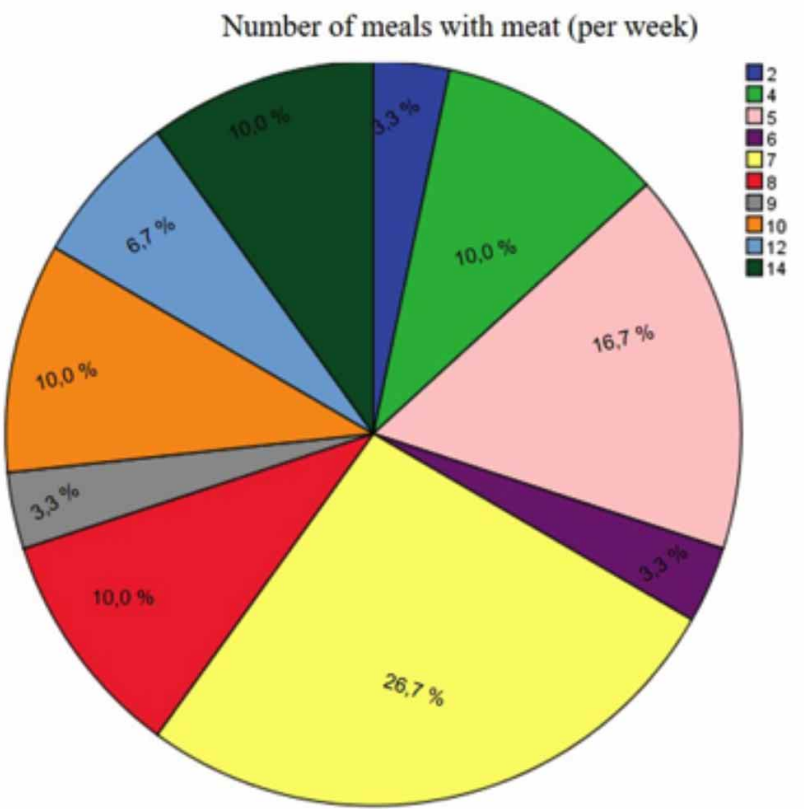

Fig. 7. Representative graph of the distribution of "Meals with meat per week", in percentage (\%)

\section{Statistical analysis of the data}

MM thickness correlating sexes. The normality statistical was previously evaluated, having obtained a value of $P=0.650$ for the thickness of the $M M$ in contraction and a $P=0.794$ for the thickness of the $\mathrm{MM}$ in relaxation. Since $\mathrm{P}>\mathrm{a}$, the values are considered statistically significant, and therefore normality is 
accepted. The mean values of MM thickness for females were $11.75 \pm 1.14 \mathrm{~mm}$ in contraction and 10.19 $\pm 1.04 \mathrm{~mm}$ in relaxation (Fig. 8, trend of normality of values obtained for females).

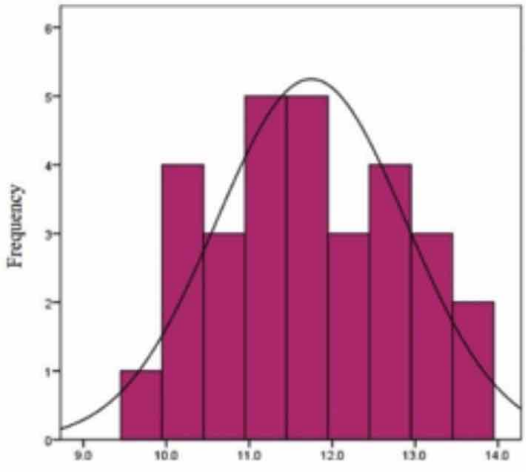

Masseter muscle (MM) thickness in contraction
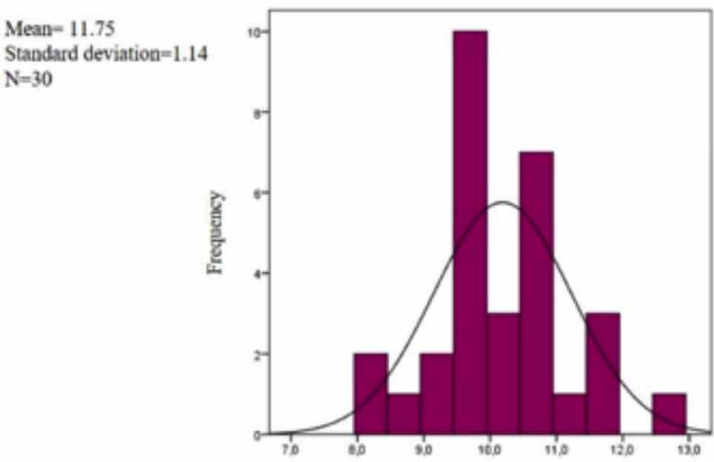

Masseter muscle (MM) thickness in rest for females (mm)
Mean $=10.19$

Standard deviation-1.03

$\mathrm{N}=30$

Fig. 8. Tendency of normal thickness of the Masseter muscle (MM) for the female sex, in contraction and at rest.

Table I Masseter muscle thickness values in females obtained by ultrasound.

\begin{tabular}{|c|c|c|c|c|}
\hline $\begin{array}{c}\text { Indivídual } \\
\text { (female sex) }\end{array}$ & $\begin{array}{l}\text { Contraction thickness } \\
\text { - right side }(\mathrm{mm})\end{array}$ & $\begin{array}{l}\text { Contraction thickness } \\
\text { - left side }(\mathrm{mm})\end{array}$ & $\begin{array}{l}\text { Thickness at rest - } \\
\text { right side }(\mathrm{mm})\end{array}$ & $\begin{array}{c}\text { Thickness at rest - left } \\
\text { side }(\mathrm{mm})\end{array}$ \\
\hline 1 & 12.8 & 13.5 & 10.2 & 9.8 \\
\hline 2 & 11.7 & 13.4 & 9.5 & 11.9 \\
\hline 3 & 10.7 & 12.1 & 9.0 & 11.5 \\
\hline 4 & 11.2 & 11.0 & 9.9 & 10.9 \\
\hline 5 & 10.3 & 11.8 & 9.5 & 9.9 \\
\hline 6 & 13.3 & 13.9 & 10.6 & 12.8 \\
\hline 7 & 11.6 & 11.8 & 9.8 & 10.7 \\
\hline 8 & 11.3 & 11.8 & 9.8 & 10.7 \\
\hline 9 & 10.9 & 11.5 & 8.4 & 9.4 \\
\hline 10 & 10.2 & 12.7 & 9.6 & 11.1 \\
\hline 11 & 12.6 & 12.9 & 11.7 & 10.0 \\
\hline 12 & 11.2 & 11.4 & 9.5 & 10.7 \\
\hline 13 & 13.3 & 10.4 & 10.4 & 8.2 \\
\hline 14 & 12.2 & 9.7 & 10.9 & 10.9 \\
\hline 15 & 10.8 & 10.0 & 8.7 & 9.9 \\
\hline
\end{tabular}

Table II Masseter muscle thickness values in males obtained through ultrasound.

\begin{tabular}{ccccc}
\hline $\begin{array}{c}\text { Individual } \\
\text { (male sex })\end{array}$ & $\begin{array}{c}\text { Contraction thickness } \\
\text { - right side }(\mathrm{mm})\end{array}$ & $\begin{array}{c}\text { Contraction thickness } \\
\text { - left side }(\mathrm{mm})\end{array}$ & $\begin{array}{c}\text { Thickness at rest - } \\
\text { right side }(\mathrm{mm})\end{array}$ & $\begin{array}{c}\text { Thickness at rest- left } \\
\text { side }(\mathrm{mm})\end{array}$ \\
\hline 1 & 14.6 & 13.5 & 12.1 & 10.8 \\
2 & 14.4 & 15.6 & 13.4 & 13.0 \\
3 & 12.8 & 12.7 & 10.3 & 10.7 \\
4 & 15.9 & 14.9 & 14.2 & 13.2 \\
5 & 12.8 & 12.7 & 10.5 & 10.1 \\
6 & 17.8 & 13.6 & 15.6 & 13.0 \\
7 & 12.9 & 9.8 & 12.2 & 8.4 \\
8 & 15.7 & 13.1 & 11.0 & 10.8 \\
9 & 15.9 & 13.1 & 11.0 & 10.8 \\
10 & 12.1 & 13.7 & 9.7 & 12.6 \\
11 & 16.9 & 14.9 & 14.5 & 10.1 \\
12 & 13.1 & 13.2 & 12.0 & 10.5 \\
13 & 14.3 & 15.2 & 13.5 & 13.3 \\
14 & 14.8 & 13.0 & 10.6 & 11.0 \\
\hline
\end{tabular}


Likewise, a value of $\mathrm{P}=0.198$ was obtained for the thickness of the MM in contraction and a $\mathrm{P}=0.222$ for the thickness in relaxation. For males, the mean
MM thickness was $13.95 \pm 1.62 \mathrm{~mm}$ in contraction and $11.64 \pm 1.68 \mathrm{~mm}$ in relaxation (Fig. 9, trend of normality of values obtained for males.

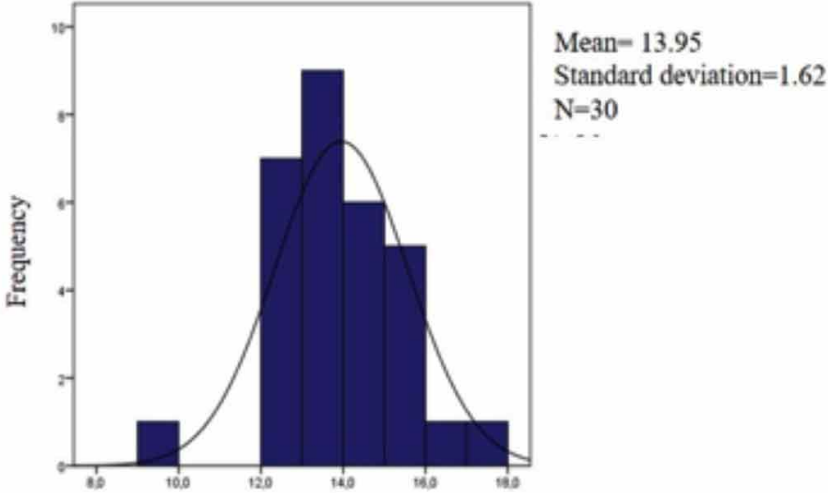

Masseter muscle (MM) thickness in contraction for males (mm)

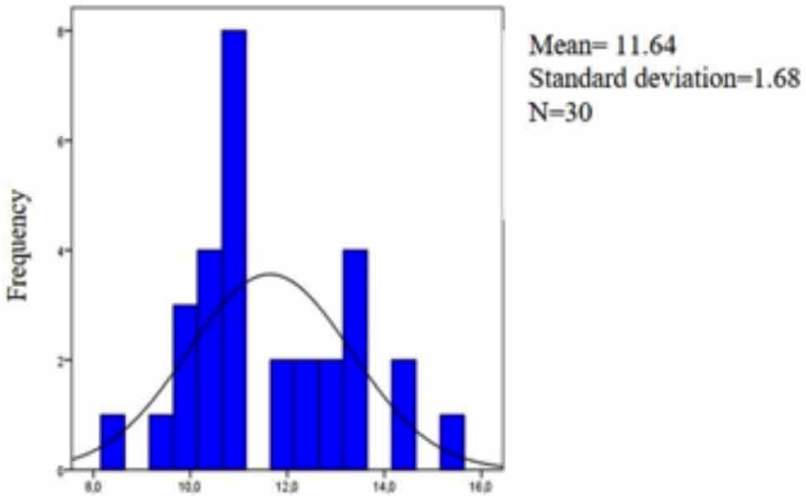

Masseter muscle (MM) thickness in rest for males (mm)

Fig. 9. Tendency of normal thickness of the Masseter muscle (MM) for the male sex, in contraction and at rest.

\section{DISCUSSION}

This research investigated the thickness of the MM using ultrasound and its relation to both sexes based on measuring protocols described in the literature and its association with nutritional habits and active or sedentary lifestyle.

In the literature, it is described that ultrasound is sufficiently sensitive to detect changes in the order of 10 to $20 \%$ in the thickness of the MM, determining morphological changes in vivo and in real time (Oliveira et al.). In addition, due to the advantages described in Table III, there is the possibility of repetition of the imaging exam when not well performed, without any biological damage to the patient, because this type of exam does not use ionizing radiation.

The heterogeneity of the masseter thickness reported in the literature is probably due to differences in sample selection, lack of standardization in the methodology, such as variation of the position and pressure of the transducer, the use of different ultrasound equipment and measurements performed by different observers (Oliveira et al.). Even so, it is possible accurately to determine the thickness of the mandibular elevator muscle following a specific protocol, carried out by an experienced appraiser, to guarantee the acquisition of values with the smallest possible error, through of the fulfillment of the defined protocol, with maximum necessary calibration (Satiroglu et al.).

According to other research, the application of a water-based gel is essential to reduce the noise of the sonogram and avoid the application of excessive pressure (Kiliaridis \& Kälebo). The perpendicular positioning of the transducer is crucial for the correct ecographic visualization, if positioned obliquely; it leads to morphological distortion with consequent measurement error (Kiliaridis \& Kälebo; Emshof et al.; Reis Durão et al.).

The linear measurements obtained in this research guarantee an estimate of the normality values for women and men. They are in accordance with the values described in the literature, showing that the menare thicker than women (Kiliaridis \& Kälebo; Bakke et al.; Ariji et al., 2004; Satirog lu et al.; Georgiakaki et al.; Palinkas et al.; Reis Durão et al.). The discrepancy in values between males and females is due to the genetic variation found between the different genders (Palinkas et al.). The muscular composition is different between men and women, with a higher percentage of type II fibers in males. These muscle fibers present a more glycolytic phenotype, with a larger diameter and a predominance of anaerobic energy metabolism. The muscle made up of this type of fiber has a higher 
contraction speed and maximum tension compared to the female muscle, which is predominantly made up of type I muscle fibers (Lexell et al., 1988; Ciciliot et al., 2013).

Studies have shown that during growth there is a tendency to gain muscle mass, instead of what happens with aging, in which there is a natural degenerative process, tendently responsible for the loss of muscle mass (Frugone et al.; Oliveira et al.; Yamaguchi et al., 2018). However, the correlation between the age of the individual and the thickness of the MM is still controversial, in this study the average age of the individuals was $23.5 \pm 2.3$ years, with a limitation, as it is a relatively age group of young adults. Because, according to data in the literature, the reduction in muscle mass of the masseter is considered stronger in individuals affected by muscle inactivity, instead of aging (Yamaguchi et al.). So, this is one of the main causes of reduced muscle mass in older individuals. Muscle fiber atrophy associated with disuse is known to involve predominantly type I fibers (Ciciliot et al.), while aging involves type II fibers (Lexell et al.). Therefore, it is possible to increase the thickness of the MM through occlusal rehabilitation in healthy elderly patients, regardless of their age (Yamaguchi et al.).

Although some studies suggest a relationship between the age factor and the thickness of the MM (Raadsheer et al.) older and male individuals have a thicker muscle (Raadsheer et al.); other authors did not find the same relationship when selecting a sample of a reduced age group (Kiliaridis \& Kälebo). On the other hand, all individuals observed present apparent occlusal stability, with no teeth other than premolars (for orthodontic reasons) or third molars being absent, as well as not having dental implants, especially removable. The balanced distribution of occlusal forces is essential for the symmetrical activation of the masticatory muscles, particularly MM, ensuring less effort and greater strength during function (Rastogi et al., 2015). Occlusal stability is translated as a functional variable, since it expresses the positive relationship between occlusal contacts and muscle thickness (Frugone et al.). Individuals with unilateral posterior crossbite have reduced MM thickness, ipsilateral to the crossbite (Kiliaridis et al.). Otherwise, premature occlusal contacts affect the masticatory function, generating an imbalance of the masticatory system, with suppression of oxygenation and accumulation of metabolic products, with consequent muscle pain (Lauriti et al., 2014).
Regarding "nutritional habits", studies point to the possibility of this variable influencing the morphology of MM (Hichijo et al., 2014; Oliveira et al.), showing that regions where the diet is fattier or essentially composed of meat, individuals tend to have greater masticatory strength and, consequently, an increase in the thickness of the masticatory muscles (Oliveira et al.). On the other hand, authors argue that the influence of diet on the stomatognathic system is visible only during growth (Hichijo et al.). Through the questionnaires it was possible to verify that $26.7 \%$ of individuals, on average, consume meat seven times a week, this may indicate that there is a relationship between MM thickness, bite force, facial morphology, presence occlusal factors (Bakke et al.) and chewing, as in this research the sample consisted of young adult individuals (mean age and $23.5 \pm 2.3$ years). Since the hypothesis of the relevance of the individual's diet, mainly the consumption of protein, can be based on the anomalous relationship of that of muscular form and function (Oliveira et al.). The deterioration of masticatory efficiency restricts the intake of proteins and carbohydrates, consequently, nutrition (Saarela et al., 2016), thus increasing the risk of malnutrition.

Nevertheless, the "lifestyle" can affect the dimensions of the MM. Dental clenching requires the activation of the jaw elevator muscles, including MM, particularly in situations that require concentration, emotional peaks, and physical activity. When prolonged, joint and muscle overload occurs, leading to pain and functional impairment (Reynolds et al., 2016). Investigations show a correlation between occlusion and posture, demonstrating that the myocentric position of the mandible is favorable to postural balance (Fujino et al., 2010). Thus, sedentary lifestyle is also one of the etiological factors for poor posture, with significant consequences for all components of the musculoskeletal structure, including the craniofacial complex.

Regular physical exercise induces changes in contractile function and muscle fiber morphology (Bex et al., 2017). When the muscle contracts against some resistance, protein synthesis is stimulated, forming cracks in the muscle fibers (Camera et al., 2017). After recovery from exercise, new proteins are produced and muscle fibers recover, becoming denser and causing muscle hypertrophy (Locatelli et al., 2017). In addition to age and genetics, other factors such as unhealthy diet, limited physical activity, and the occurrence of chronic diseases also contribute to the loss of muscle mass and decreased muscle strength (Goodpaster et 
al., 2006). Other authors have found a positive correlation between masticatory ability and physical activity in elderly patients. In a study that showed the efficiency of MMs related to physical fitness in these patients (Gaszynska et al., 2014).

The following limitation of this study must be mentioned: the reduced sample within the groups (female and male) made it difficult to analyze a precise relationship between lifestyle and diet related to MM thickness. On the other hand, the findings reported here expand directions for future research on the influence of the muscle activity of masticatory muscles, the interconnection among eating habits, the sedentary lifestyle, and the characteristics of dental occlusion.

In this study, individuals with significant changes in the craniofacial complex were excluded, especially the cases with signs and / or symptoms of temporomandibular disorders. The presence of this pathological condition is responsible for a change in the stomatognathic complex, generating an imbalance in the temporomandibular joint, with consequent intramuscular modulation (Aldemir et al.; Ariji et al., 2004; Georgiakaki et al.). Muscle pain and fatigue are responsible for restricting function, preventing the maximum voluntary contraction of the MM as well as its relaxation, leading to a sub-measurement of thickness values ??(Ariji et al, 2010.).

The location of the masseter was determined by its palpation in relaxation and contraction (Bertram et al., 2003), followed by placement of the transducer for confirmation, asking the patient to repeat the alternate muscle movement, to distinguish between the skin and the muscular fascia (Close et al.). The MM is identifiable as a homogeneous structure, comprised between the skin and the mandible branch, easily perceived (Kiliaridis \& Kälebo).

The values obtained in this study, female with $11.75 \pm 1.14 \mathrm{~mm}$ in contraction and $10.19 \pm 1.04 \mathrm{~mm}$ in relaxation and male with $13.95 \pm 1.62 \mathrm{~mm}$ in contraction and $11.64 \pm 1.68 \mathrm{~mm}$ in relaxation, are similar to those found by other authors (female with $11.55 \pm 0.5 \mathrm{~mm}$ in contraction and $8.8 \pm 0.3 \mathrm{~mm}$ at rest and male with $14.2 \mathrm{~mm} \pm 0.4 \mathrm{~mm}$ in contraction and $10.95 \pm 0.3 \mathrm{~mm}$ at rest (Palinkas et al.), showing ultrasound as a precise method, but with reduced reproducibility in the relaxed mode, which can be explained by the fact that the muscle be highly susceptible to pressure applied by the transducer (Bertram et al.; Emshof et al.; Kiliaridis \& Kälebo; Oliveira et al.), in addition to the variability of the resting position performed by individuals (Emshof et al.). On the other hand, the measurement in maximum intercuspation requires the significant collaboration of the patient to maintain occlusal contacts with maximum contraction. the MM (Kiliaridis \& Kälebo), which translates into the maximum muscle thickness (Palinkas et al.).

Despite the data obtained, further studies are needed to support the evidence of the influence of diet on muscle development, while still allowing the distinction between different dietary regimes and the development phase in which the effect becomes more evident. In addition, the facial type will be considered in future studies, to enhance the diagnosis of masseter muscle pathology.

From the data obtained in this study and correlating them with the literature, it was possible to prove the reliability of the ultrasound in determining the thickness of the MM since a standardized measurement protocol was used. However, the values obtained through this method may vary according to ethnicity, different age groups, gender, and body mass index of individuals in a population.

DURÃO, A. P. R.; RIBEIRO, M. D. A.; MIRANDA, M. \& MOROSOLLI, A. R. C. Evaluación de las dimensiones del músculo masetero mediante ultrasonido. Int. J. Odontostomat., 15(4):980-988, 2021.

RESUMEN: El objetivo de este estudio fue determinar los valores medios del grosor del músculo masetero, en reposo y contracción, en hombres y mujeres sanos. Inicialmente se distribuyeron 102 cuestionarios entre los estudiantes. Se seleccionaron 30 pacientes, 15 hombres y 15 mujeres, según los criterios de inclusión, excluyendo a todos los individuos con síntomas de disfunción temporo-mandibular o síndromes con alteraciones craneofaciales. El grosor del músculo masetero se determinó de forma bilateral, en reposo y contracción. Como punto de referencia para la medición del espesor (plano axial), la prolongación posterior de la comisura labial. Los valores de normalidad del músculo masetero en las mujeres fue de $11,75 \pm 1,14 \mathrm{~mm}$ en contracción y 10,19 $\pm 1,04 \mathrm{~mm}$ en relajación; y en los varones $13,95 \pm 1,62 \mathrm{~mm}$ en contracción y 11,64 $\mathrm{mm} \pm 1,68 \mathrm{~mm}$ en relajación. Los resultados obtenidos coinciden con los descritos en la literatura, señalando la precisión y reproducibilidad del ultrasonido si se aplica un protocolo, principalmente dirigido a controlar la presión aplicada por el transductor.

PALABRAS CLAVE: músculo masetero, ecografía, espesor, morfología craneofacial. 


\section{REFERENCES}

Aldemir, K.; Üstüner, E.; Erdem, E; Demiralp, A. S. \& Oztuna, D. Ultrasound evaluation of masseter muscle changes in stabilization splint treatment of myofascial type painful temporomandibular diseases. Oral Surg. Oral Med. Oral Pathol. Oral Radiol., 116(3):37783, 2013.

Ariji, Y.; Katsumata, A.; Hiraiwa, Y.; Shimizu, M.; Kurita, K. \& Ariji, E. Masseter muscle sonographic features as indices for evaluating efficacy of massage treatment. Oral Surg. Oral Med. Oral Pathol. Oral Radiol., 110(4):517-26, 2010.

Ariji, Y.; Sakuma, S.; Izumi, M.; Sasaki, J.; Kurita, K.; Ogi, N.; Nojiri, M.; Nakagawa, M.; Takenaka, M.; Katsuse, S.; et al. Ultrasonographic features of the masseter muscle in female patients with temporomandibular disorder associated with myofascial pain. Oral Surg. Oral Med. Oral Pathol. Oral Radiol. Endod., 98(3):337-41, 2004.

Bakke, M.; Tuxen, A.; Vilmann, P.; Jensen, B. R.; Vilmann, A. \& Toft, M. Ultrasound image of human masseter muscle related to bite force,electromyography, facial morphology, and occlusal factors. Scand. J. Dent Res., 100(3):164-71, 1992.

Bertram, S.; Brandlmaier, I.; Rudisch, A.; Bodner, G. \& Emshoff, R. Crosssectional characteristics of the masseter muscle: an ultrasonographic study. Int. J. Oral Maxillofac. Surg., 32(1):64-8, 2003.

Bex, T.; Baguet, A.; Achten, E.; Aerts, P.; De Clercq, D. \& Derave, W. Cyclic movement frequency is associated with muscle typology in athletes. Scand. J. Med. Sci. Sports, 27(2):223-9, 2017.

Camera, D. M.; Burniston, J. G.; Pogson, M. A.; Smiles, W. J. \& Hawley, J. A. Dynamic proteome profiling of individual proteins in human skeletal muscle after a high-fat diet and resistance exercise. FASEB J., 31(12):5478-94, 2017.

Ciciliot, S.; Rossi, A. C.; Dyar, K. A.; Blaauw, B. \& Schiaffino, S. Muscle type and fiber type specificity in muscle wasting. Int. J. Biochem. Cell Biol., 45(10):2191-9, 2013.

Close, P. J.; Stokes, M. J.; L'estrange, P. R. \& Rowell, J. Ultrasonography of masseter muscle size in normal young adults. J. Oral Rehab., 22(2):128-34, 1995.

Emshoff, R.; Emshoff, I.; Rudisch, A. \& Bertram, S. Reliability and temporal variation of masseter muscle thickness measurements utilizing ultrasonography. J. Oral Rehabil., 30(12):1168-72, 2003.

Frugone, R. A.; Valenzuela, H. P. \& Retamal, V. Masseter muscle dimensions measured by ultrasound per sex. Rev. Fac. Odontol. Univ. Antioq., 22(1):7-11, 2010.

Fujino, S.; Takahashi, T. \& Ueno, T. Influence of voluntary teeth clenching on the stabilization of postural stance disturbed by electrical stimulation of unilateral lower limb. Gait Posture, 31(1):122-5, 2010.

Gaszynska, E.; Godala, M.; Szatko, F. \& Gaszynski, T. Masseter muscle tension, chewing ability, and selected parameters of physical fitness in elderly care home residents in Lodz, Poland. Clin. Interv. Aging, 9:119-203, 2014

Georgiakaki, I.; Tortopidis, D.; Garefis, P. \& Kiliaridis, S. Ultrasonographic thickness and electromyographic activity of masseter muscle of human females. J. Oral Rehabil., 34(2):121-8, 2007.

Goodpaster, B. H; Park, S. W.; Harris, T. B.; Kritchevsky, S. B.; Nevitt, M.; Schwartz, A. V.; Simonsick, E. M.; Tylavsky, F. A.; Visser, M. \& Newman, A. B. The loss of skeletal muscle strength, mass, and quality in older adults: the health, aging and body composition study. J. Gerontol. A Biol. Sci. Med. Sci., 61(10):1059-64, 2006.

Hichijo, N.; Kawai, N.; Mori, H.; Sano, R.; Ohnuki, Y.; Okumura, S.; Langenbach, G. E. \& Tanaka, E. Effects of the masticatory demand on the rat mandibular development. J. Oral Rehabil., 41(8):581-7, 2014.

Kiliaridis, S. \& Kälebo, P. Masseter muscle thickness measured by ultrasonography and its relation to facial morphology. J. Dent. Res., 70(9):1262-5, 1991.

Kiliaridis, S.; Mills, C. M. \& Antonarakis, G. S. Masseter muscle thickness as a predictive variable in treatment outcome of the twin-block appliance and masseteric thickness changes during treatment. Orthod. Craniofac. Res., 13(4):203-13, 2010.
Kubo, K.; Kawata, T.; Ogawa, T.; Watanabe, M. \& Sasaki, K. Outer shape changes of human masseter with contraction by ultrasound morphometry. Arch. Oral Biol., 51(2):146-53, 2006.

Lauriti, L.; Motta, L. J.; de Godoy, C. H. L.; Biasotto-Gonzalez, D. A.; Politti, F.; Mesquita-Ferrari, R.; Santos Fernandes, K. P. \& Bussadori, S. K. Influence of temporomandibular disorder on temporal and masseter muscles and occlusal contacts in adolescents: an electromyographic study. BMC Musculoskelet. Disord., 15:123, 2014.

Lexell, J.; Taylor, C. \& Sjöström, M. What is the cause of the ageing atrophy? Total number, size and proportion of different fiber types studied in whole vastus lateralis muscle from 15 - to 83 -year-old men. J. Neurol. Sci., 84(2-3):275-94, 1988.

Locatelli, J.; Paiva, N. C. N.; Carvalho, S. H. R.; Lavorato, V. N.; Gomes, L. H. L. S.; Castro, Q. J. T.; Grabe-Guimarães, A.; Carneiro, C. M.; Natali, A. J. \& Isoldi, M. C. Swim training attenuates the adverse remodeling of LV structural and mechanical properties in the early compensated phase of hypertension. Life Sci., 187:42-9, 2017.

Oliveira, J. H. P.; Dourado-Filho, M. G.; Melo, T. M. A.; Lima, N. S.; Marcelino-Filho, M. \& Silva, H. J. Evidence of measures of normalcy for thickness of masseter muscle evaluated with ultrasound: a review study. Rev. CEFAC, 17(1):238-52, 2015.

Palinkas, M.; Nassar, M. S. P.; Cecílio, F. A.; Siessere, S.; Semprini, M.; Sousa, J. M.; Hallak, J. E. C. \& Hallak Regalo, S. C. Age and gender influence on maximal bite force and masticatory muscles thickness. Arch. Oral Biol., 55(10):797-802, 2010.

Raadsheer, M. C.; Kiliaridis, S.; Van Eijden, T. M.; Van Ginkel, F.C. \& Prahl-Andersen, B. Masseter muscle thickness in growing individuals and its relation to facial morphology. Arch. Oral Biol., 41(4):323-32, 1996.

Rastogi, A.; Srivastava, S.; Gaur, A.; Dupare, A.; Rastogi, S. \& Kamatagi, L. Electromyographic evaluation of the effect of lined dentures on masticatory muscle activity in edentulous subjects. J. Clin. Diagn. Res., 9(8):ZC80-3, 2015.

Reis Durão, A. P.; Morosolli, A.; Brown, J. \& Jacobs, R. Masseter muscle measurement performed by ultrasound: a systematic review. Dentomaxillofac. Radiol., 46(6):20170052, 2017.

Reynolds, A. K.; Nickel, J. C.; Liu, Y.; Leeper, D. K.; Riffel, K. M.; Liu, H. \& Iwasaki, L. R. Sex differences in jaw muscle duty factors during exercise in two environments: A pilot study. J. Electromyogr. Kinesiol., 30:15-22, 2016.

Saarela, R. K.; Lindroos, E.; Soini, H.; Hiltunen, K.; Muurinen, S.; Suominen, M. H. \& Pitkälä, K H. Dentition, nutritional status, and adequacy of dietary intake among older residents in assisted living facilities. Gerodontology, 33(2):225-32, 2016.

Satirog lu, F.; Arun, T. \& Is, ik, F. Comparative data on facial morphology and muscle thickness using ultrasonography. Eur. J. Orthod., 27(6):562-7, 2005.

Yamaguchi, K.; Tohara, H.; Hara, K.; Nakane, A.; Kajisa, E.; Yoshimi, K. \& Minakuchi, S. Relationship of aging, skeletal muscle mass, and tooth loss with masseter muscle thickness. BMC Geriatrics, 18:67, 2018.

Correponding author:

Aline Rose Cantarelli Morosolli

Av. Ipiranga, 6681 Prédio 6

Dentistry Course

School of Health and Life Science - Partenon

Pontifical Catholic University of Rio Grande do Sul (PUCRS)

Porto Alegre - RS

BRAZIL

Email: aline.morosolli@pucrs.br

https://orcid.org/0000-0001-6622-9594 